\title{
And Yet They Persist; Lidar Bare-Earth DEMs Elucidate Carolina Bay Rims As Palimpsest Features Controlling Their Topographic Expression Through Differential Weathering And Erosion
}

Paper No. 32-10, 2018 GSA Southeastern Section Meeting, Knoxville, TN 12-13 April, 2018

Authors: Michael E. Davias, michael@cintos.org,Thomas H.S. Harris, thsharris@mindspring.com

\section{Abstract}

Carolina bays have long been recognized as oriented oval basins. A comprehensive survey of the bays (Survey) using LiDAR bare-earth digital elevation maps (DEMs) has documented their planforms as conforming robustly to a handful of ovoid shapes which diverge from an ellipse by subtle, yet distinctive markers. These shapes are cast as six archetypes, each found to be applicable to a specific geographic region. We note that many bays with complete circumferential planforms lack raised rims, but instead are simply basins sunken into a terrace. Using the archetype templates, the Survey has identified vast numbers of basins that echo the shape and orientation of nearby well-described Carolina bays, but are not hydraulically closed. We propose that when fluvial headward erosion succeeds in breaching into a bay basin, a "valley head basin" is formed. Carolina bay raised rims appear to the naked eye to be gently arcing embankments, yet the LiDAR DEMs show them to be robust landforms tracking precisely to the archetype planform for kilometers. We speculate that these basins possess a palimpsest structural lithology that subdues the gradualistic mechanisms seeking to eradicate them by controlling their own topographic expression through differential weathering and erosion. We discuss cases where bay perimeters seem to control the extent and paths of surficial sheet and fluvial erosion, both within and around the bay. Also, we discuss bays whose identity is hidden by burial in fluvial or marine transgressive deposits, yet the LiDAR exposes their existence as ghostly traces of their properly oriented and shaped rims. These findings suggest to us that Carolina bays are not wispy gradualistic landforms of recent age, but are perhaps medial ejecta artifacts of the same Mid Pleistocene Transition Impact event that created the Australasian Tektites as distal ejecta. Our goal is to encourage the interrogation of Carolina bay age and geomorphology through deep coring and application of cosmogenic isotope dating techniques. Metrics for $~ 51,000$ surveyed bays are available from a Google Fusion Table: https://goo.gl/XTHKC4 . Individual bays are geospatially referenceable using a hyperlinked map to display their metrics and enable visualization of the associated DEM imagery and planforms on a virtual globe: https://goo.gl/EHR4Lf .

\section{Goals For Talk}

- A Morphometric Survey of the Carolina bays

- A Catastrophic hypothesis for the Carolina bays

- Update: Carolina bay Geospatial Survey

- LiDAR DEM and Carolina Bay Identification

- Foundational Rim as Palimpsest Features Controlling Topographic Expression

- Valley Head Basins - Pirated Carolina bays?

- Reviewing the Evidence \& Falsification approaches

- The Tektites

- Summary

All work product freely available @ cintos.org 


\section{Introduction}

Greetings: Today I would like to discuss my Carolina bay Survey, and how using high-resolution digital elevation maps might help us see their true nature.

"No one has yet invented an explanation which will fully account for all the facts observed" Douglas Johnson, 1942

"Their very randomness of grouping and scatter demands an explanation. As a statistical phenomenon, they deserve to be studied statistically." W.C. Rasmussen, 1953

The comprehensive Geospatial and Morphometric Survey of the Carolina bays has provided the statistics to inspire Johnson's "invention". Our working hypothesis holds that the bays were collateral damage from the Mid-Pleistocene Transition Impact:

Carolina bays are not ephemeral, wispy landforms, but rather represent the surface topology of a sheet of unconsolidated quartzose sediment, deposited as a geophysical mass flow of ejecta during the Mid Pleistocene Transition impact event $780 \mathrm{ka}$. The planforms and orientations have been robustly imprinted into the landscape, and have resisted ongoing erosional and accretionary processes.

While our working hypothesis holds the Carolina bays to be far older than orthodoxy allows, modeling such great antiquity may provide a resolution by placing them deeper into the surficial sedimentary stack.

This working hypothesis offers correlation with what is likely the largest cosmic impact on the planet since the end-cretaceous. Isotopic analysis of the distal ejecta from that event, the Australasian tektites, demands they were hewn from continental crust. Implausibly, after 50 years of searching, they are missing a corelated impact structure; quite an unlikely situation for an event "just yesterday", geologically. We ask: are the "experts" looking for it in the wrong hemisphere?

Dr. Johnson got one "fact observed" egregiously wrong. Throughout the most intensive period of Carolina bay investigations, the 1930s into the 1970s, the mere suggestion of large catastrophic impacts was considered geological heresy.

When Johnson examined the Carolina bays in 1940, he stated, with his authority as Executive Officer of Columbia University's Department of Geology:

"The largest meteorites known to have reached the earth measure less than a score of feet in maximum diameter" Douglas Johnson, 1940

Were catastrophic solutions given a fair hearing? Dare I say "banished"? And what about today? Well, we do have this venue ....and for that I am grateful! 


\section{Carolina Bay Geospatial Survey}

Here is a Google Fusion Table web page that links to each of the 51,000 bays in the survey.

\section{[ http://cintos.org/SurveyBayMap ]}

Clicking on a placemark yields the bay's metrics and links to the source overlays for presentation on the virtual globe. Another map links to the data, geospatially organized into $1^{\circ}$ USGS quadrants.

\section{[ http://cintos.org/SurveyQuadMap ]}

This image shows the hsv-shaded maps I generate for interrogating the bay landscape stripped of vegetation, using Google Earth. The bay planform found in this area is my "baySouth" archetype.

Note three things - how well this planform template matches these bays; the bays are generally set into the surrounding pediment and show no "raised rim"; and except for the large bay on the center right, none have evidence of attendant dune formations on their southeastern rims. Network Linked Overlays allow capture the bay rim. They are positioned for length, width and rotation using the Green adjustment handles. Please note the tightness of the fit. This is not cherry-picking; the vast majority of measured bays fit this robustly.

The element is extracted as textual metadata and interrogated for the archetype link, the bounding box corners and a rotational value. Using trig on the bounding box yields a major and minor axis, an approximate centroid. The rotation value is re-applied when rendering on Google Earth. We maintain an on-line a directory with 51,000 kml files for these overlays - one for each measured bay. The appropriate one for each measured bay in the survey is retrievable for presentation on the virtual globe via the popup link from the Survey's geospatial map previously discussed.

In the 1940's, Johnson documented two bay shapes, each found in unique territories. I have identified six species of the Carolina Bay genus. Each of these species are found to be adhered to robustly within a given region, yet they are occasionally found with hybrid characteristics as one species yields to another. Just as most species come in a variety of sizes, so do the bays.

The length and width of these overlay templates can be shrunk or stretched to match the size of a given bay without altering the unique ovoid archetypes.

Here is the current distribution of bays by planform.

This is a log-log histogram of bays by major axis, plotted for seven 25 meter elevation ranges, plus the collection of bays found at $200 \mathrm{~m}$ above sea level on The Ridge in SC. Their similarity suggests common family membership.

One of the primary rationales for executing the Survey was to obtain high-resolution data on the orientation of the bays, and this inverse distance weighted map documents them rotating $\sim 75$ degrees clockwise from New Jersey down to Alabama. These data supports the "Systematic by latitude" rotation in the bay's orientation seen by many workers over the years.

Here, we place our posited impact site on Michigan's Lower Peninsula during the depths of MIS 20. As we rotate clockwise, there is a fairly consistent radial placement of the bays along the annulus of their distribution.

In this graph, we plot the measured orientation of 51,000 bays on the y axis against the clockwise angle subtended as we sweep through the $14^{\circ}$ spatial quadrants (green dots) the bays reside in. When adjusted properly for Coriolis steering, the bays seem to be telling us where they originated from. The linear nature of this plot from New York clockwise to Nebraska provides evidence of the relationship between the Carolina bays and Nebraska's Rainwater basins. 


\section{LiDAR DEM and Carolina Bay Identification}

LiDAR DEMs are an exciting development in geology. Here we see the Emporia Airport, Southeastern Virginia. A fellow researcher had asked me for a LiDAR image to help him identify any archeological sites in peril due to a planned runway expansion. Unfortunately, the upper left area has no LiDAR and the available 10 meter data provided no guidance. The lower right does have sub-meter LiDAR.

While preparing this, I noticed a heavily eroded Carolina bay looming. Back out and track the overlay, and the declaration becomes a "bit" less subjective.

Now let's look at the arcuate segment on the lower right. What is this??? I interpret it as an eroded rim segment surviving on a flood plain. Zooming out shows it is a 700 meter rim segment of an eroded 3.3 kilometer bay, a virtual twin to the airport's bay. The overlay tracks perfectly for over 6 kilometers along the surviving rim.

Here is an elevation profile map along that rim. It maintains a formidable presence 20 meters above the eroded remnant on the river floodplain. And it is successfully controlling erosion inside and outside of the bay, along its full extent. That would be a formidable performance for a wispy, ephemeral landform.

An elevation profile across the cleared rim demonstrates that it's symmetrical, and having a relief of $\sim 2.5$ meters.

From the arrow, let's look 700m northward.

Note the gentle rise and fall of the fence line left to right The owner reported to me that it was drudgery to drill those post holes, as the sandy soil is tightly compacted.

But what is it? I posit it is a Foundational Rim. 


\section{Foundational Rim as Palimpsest Features Controlling Topographic Expression}

Let me explain with a cross section cartoon. We start with an antecedent surface and Build a catastrophic deposit with an embedded Carolina bay void.

I speculate there exists a Foundational Rim, a zone of higher compaction lining the basin void, likely due to the energetic depositional mechanism.

Over time, the closed basin hydrates and deep layers of peat are formed. This LiDAR image reflects my definition of a Carolina bay - a depression in a pediment.

This is a graphic from Dr. Johnson's book, where he documents a typical bay's border as a broad flattopped rim. Where are the parabolic sand dunes that are so aggressively sought out by Carolina bay researchers? Could they only be ephemeral surficial modifications unrelated to the origin of the bays?

Consider 800,000 years of "Rinse \& repeat", with eolian sheet deposits, more peat, toss in inundation in an embayment, or flood plain environment. Eventually, the peat will decompose and compact.

Voila! The palimpsest topography persists . Think kettle hole. Given such a morphology... how far down must a core penetrate to reach the antecedent surface? And what collection of various gradualistic processes will that core register before encountering the controlling Foundational rim?

Let's look at some examples of buried bays

... in the Cape Fear River Valley

.. in the Chesapeake bay, as noted by Cooke, barely poking above the surface on the left- while they present crisply on Virginia's Eastern Shore to the right.

....in the drainage around Lake Waccamaw they are subtle in the LiDAR. Yet those ghostly bays persist in the Infrared, conforming robustly to the bayCarolina archetype.

I do not interpret Lake Waccamaw to be a "Carolina bay". It's shoreline bears all the hallmarks of a gradualistic geomorphology -random wind shaped arcs connected by ragged lineals. It's floor has been found to be laced with relic paleochannels associated with the two drainage basins that merge at its location. At 9.5 kilometers on major axis, it would be - by a large margin - the most expansive Carolina bay. Sadly, workers often present Lake Waccamaw as the poster boy for Carolina bays, and in doing so completely dismiss the robustness of planforms inherent in the real Carolina bays. I'll come back to this mis-identification later in the talk.

Bays do exist with raised rims. Back to the cross sectional comic to explain a possible morphology.

Let's provide for hundreds of thousands of years of sheet erosion downslope towards a drainage basin off to the left.

Eventually the erosion differentially un-roofs the foundational rim, while other parts of the rim are unaffected. As an example, here is a series of bays in South Carolina, Southeast of Latta. While erosion exposes their rims on southwest, these bays remain imbedded in the pediment to the northeast. We note the absence of any "prominent sand dunes on the southeastern rim".

In the near future, these bays will be dissected by the construction of Interstate 73, although the largest will be spared after a successful battle by the locals to preserve its wetlands.

The US Supreme Court has ruled that Carolina bays are not protected by the Clean Water Act, because they are isolated wetlands. Hence there are only a vanishingly small percentage of unmolested bays surviving. 
Now, we do see bays which have had their entire rim unroofed. On the DelMarva Peninsula, an unroofed rim is being actively mined for sand.

The elevation transect across a surviving rim on the western side shows a familiar symmetrical profile.

Raymond Daniels and his associates from NC State cored Goldsboro Ridge, NC in the 1970's. That work led me to the concept of a depositional sheet that contains the bays. Note the unroofed rims perched above the lower terrain.

Here are their drawings, with the Goldsboro sand resting on the Sunderland. A 7,000 ft traverse across the ridge, and a 5-mile run along the ridge were evaluated.

The A-F sequence notes cores across a Carolina Bay. Which they stated does "not disturb the underlying Sunderland materials."

The resulting paper The Goldsboro Ridge, an Enigma presents a conflicted gradualistic explanation vacillating between marine, fluvial or eolian.

\section{"Even the Carolina Bays do not disturb the underlying Sunderland materials."}

"Therefore, these Carolina Bays are merely surface features associated with the formation of the ridge." Daniels, Gamble and Wheeler, 1971

Green Pond Bay, NC, is $1.55 \mathrm{~km}$ on major axis and is located near the inflection in the NC-SC border. It is being attacked by sheet and headward erosion approaching from the southwest. The persistent symmetrical unroofed rim arcs exquisitely for almost a kilometer.

The area is heavily swathed in dune formations, yet none are seen associated with the rim; the bay remains hydraulically sound, and no dunes encroach into its interior.

It has been recently clear-cut and treated to an extensive network of drainage and road beds. A good number of Pond Cypress were preserved. The property is under private ownership, and attempts by the State to apply a preservation plan have failed.

We proceed with the $2 \mathrm{D}$ cartoon with the eventual penetration of the bay rim by headward stream erosion, and the basin fill begins to erode out. The One kilometer long Sandy Grove Bay shows such an invasion.

In the transect profile, we see the head of the drainage in the bay's center is 25 meters above the nearby outfall. How long ago did this host wind \& wave on a flat, level terrace? I suggest we should find out.

We are on the rim of the Midlothian terrace, southwest of Richmond, where numerous Carolina bay landforms have long been noted. The collection falsifies the direct impact mechanism, as the bays lie in the sandy loam upper member of the Upland Gravels. There is bedrock immediately below the gravel member, so there is no impact crater here.

An elevation transect using the LiDAR data demonstrates the presence of a symmetrical foundational rim controlling the headward erosion both inside and outside of this bay.

The survey documents vast quantities of heavily eroded bays that have been previously overlooked. Satellite imagery shows nothing, but in the LiDAR a bay jumps out - two and three quarters of a kilometer and conforming robustly to the archetype shape.

Blythe bay, in Wilmington, North Carolina. I don't mean the little $1 \mathrm{~km}$ bay at the bottom left. Blythe is $3 \mathrm{~km}$ across. Coring in the 1940s by B.W. Wells at the center of this bay documents the bay being invaded by the Atlantic through the breach at the 2 o'clock position, which led to the deposition of a marine sediment delta within its interior, 12 meters above the current sea level. 
Wells reported that subsequent to the bay's genesis:

"five and a half feet of peat developed", and some time later...

"... with the rise of the sea ..., estuary tidal currents charged with fine sand silt and clay from the nearby mouth of the Cape Fear River became deposited over the peat to a maximum depth of seven and a half feet."

When did that transpire? It should be easy to tell with Beryllium burial dating. Wells found only carbon dead peat, and suggested a date of 250,000 years ago based on pollen samples.

We suggest that the drainage of the bay has allowed dunes from the Cape Fear River to the west to penetrate into the bay. In every case identified in the survey where eolian dunes are found to have successfully moved onto a bay floor, that bay had been breached and drained by headward erosion. We maintain that a hydraulically closed bay will adsorb - and distribute across its floor - any attempt at slow invasion by an eolian dune field, as seen in the smaller bay to its south.

That $1 \mathrm{~km}$ bay has been successfully gentrified since this LiDAR was flown. It now hosts an expansive residential and commercial shopping/entertainment complex, just like its big brother to the north. The LiDAR documents $3 / 4 \mathrm{~km}$ of unroofed foundational rim on its southwest flank, where it is being differentially eroded downslope.

A good part of that unroofed rim has been bulldozed to help fill the basin for construction. The overlay maps the former rim location. A cross rim exposure has been excised on the far left in this image. This would certainly make a grand expedition for Beryllium dating.

Lets look at some more large invaded bays. Headward erosion is found coming from all quadrants. Note how the rim controls the erosion inside these massive basins, each hard to discern without the LiDAR and the overlay because they hold little water. And sometimes streams skirt around the foundation rim, having failed to penetrate it.

This is McMurtrey Marsh, with a Major axis $3.8 \mathrm{~km}$. It conforms to my "bayWest" archetype - an oval with a slightly flattened northeast rim.

As noted by the late Bill Zanner, the Rainwater Basins in Nebraska are analogs of Carolina bays. Dr. Zanner's associate Mark Kuzila took an extensive set of cores across the rims of two, declaring that:

"The modern landscape has evolved from the loessial burial of paleobasins ... The present landscape is slightly smoother than the paleolandscape ... The shape of the present land surface is a direct result of 2.5 to 8 m of loess deposition on an ancient landscape.” Mark Kuzila, 1994

When was the controlling paleo landscape first formed? I've asked Dr. Kuzila if he would be interested in applying beryllium burial dating across those deep cores, but he has retired and stated it would be left to the next generation of researchers.

When Moore and his associates discussed "the Quaternary Evolution Of Herndon Bay" in a 2016 paper, they ran a Ground Penetrating Radar transect across the vertical relief within the blue ovals on this elevation profile map.

Their GPR traces terminated when they reached the "mud" identified in previous coring work. Rather than being a level paleo surface, that "mud" is clearly shown controlling the vertical relief of the sampled rims. What is really controlling the relief? Inquiring minds want to know. 


\section{Valley Head Basins - Pirated Carolina bays?}

I concede that when extensively eroded, the smaller bays' archetype overlays are more subjective a fit.

“These valley-head basins may have steep, scarped walls, resembling sinkholes, or Carolina Bays, or a combination of the two.”- Kathleen Farrell, 2015

Dr. Farrell has referred to these as "Valley-head basins". More recently she has referred to "Pirated Carolina Bays", which I find to be an apt description.

Stream heads don't normally terminate in nearly-closed basins. I consider them former Carolina bays that were pirated by drainage advancing into them over the past 800,000 years.

I invite you to access the Survey and carefully examine the overlays to see the exquisite fit obtained. Note that only two of these four are actually in the survey currently. They Persist, and are asking politely not be ignored any longer. 


\section{Review of the MPT Impact hypothesis - Evidence \& Falsification approaches}

Carolina bays are not ephemeral, wispy landforms, but rather represent the surface topology of a sheet of unconsolidated quartzose sediment, deposited as a geophysical mass flow of ejecta during the Mid Pleistocene Transition impact event $~ 780 \mathrm{ka}$. The planforms and orientations have been robustly imprinted into the landscape, and have resisted ongoing erosional and accretionary processes.

It would seem the working hypothesis could be easily falsified using evidence in hand.

1. "there is no erosion!"

2. "dating of bay sediments does not supported a singular event!"

3. "there are no depositional sheets across terrace boundaries"

4. "bays are too shallow and not round as required by an impact event"

5. "their geomorphology is identical to landforms elsewhere"

6. "they don't look that old!"

We suggest those would be based on misunderstandings. Let's examine each of these one by one.

1. "there is no erosion!"

The vast majority of bays have undergone significant modification, being subjected to 800,000 years of surficial eolian, lacustrine and fluvial surficial deposits. Headward stream erosion is actively dissecting the terraces they were formed on, and breaching bays to form Valley-Head Basins. As we have demonstrated here, great quantities of bays are only recognizable as bays when viewed in LiDAR.

\section{2. "dating of bay sediments does not supported a singular event!"}

Earlier tools of C14 and OSL dating often yield only "no younger than" ages, and have been applied to surficial sediments arriving over the $800 \mathrm{ky}$ of existence.

\section{3. "there are no depositional sheets across terrace boundaries"}

Efforts to declare surficial sediment providence are historically segregated by individual States and more importantly - by individual terraces.

As an example, Daniels, et al, when examining the Brandywine, Coharie, and Sunderland MSUs, stated "we believe that the surface deposits in the Middle Coastal Plain in our area are one formation, not three."

"The Brandywine, Coharie, and Sunderland MSU are delineated largely on the basis of the Kenly and Wilson Mills scarps (Table 1), which break the Middle Coastal Plain into three major surfaces. Earlier workers mapped these MSU as separate formations, but little proof has been presented that indicates one way or another what happens to the units across these scarps."

"Based on the general characteristics of the sediments, and the absence of conclusive evidence of any significant lithologic changes of sediments across the scarps in all areas, we believe that the surface deposits in the Middle Coastal Plain in our area are one formation, not three as previously believed." - Daniels, Gamble, Wheeler \& Holzhey, 1972 


\section{4. "bays are too shallow and not round as required by an impact event"}

The hypothesis presents a case for the bays being a by-product of a cosmic impact event, rather than being primary or secondary impact structures. I fully admit I don't have all the physics solved, but I maintain science should pursue an alternative cosmic hypothesis.

It has been only 50 years since geologists allowed that anything over 20 feet in diameter ever hit the earth. I maintain that science does not yet have all the answers as to how truly massive cosmic impacts unfold.

Numerous astrophysics had prognosticated as to how the comet P/Shoemaker-Levy 9 fragment train would interact with Jupiter in 1994. All were proven wrong when Earth-sized plumes erupted.

\section{5. "their geomorphology is identical to landforms elsewhere"}

Many workers declare that the Carolina bays are identical in nature to the aligned lakes on the Arctic coast, the clamshell Playa Lakes in Chile, as well as the "salt lakes" in Australia. Unlike those lakes, the Survey DEMs show the Carolina bays to be robustly constrained to a handful of well-defined planforms.

Just recently, one of the most ardent catastrophists assured me that he was convinced that the oriented periglacial lakes along the Arctic Ocean have the same geomorphology as the Carolina bays. However, planform examinations show many are rectilinear, and display the rag-tag results to be expected of gradualistic processes. It's like saying a kangaroo descended from a Tyrannosaurus Rex because they primarily stand on their hind legs.

The playas in Australia are all known to lie within well-developed drainage floodplains. Huddlestun commented on those lakes:

\section{"Some of the salt lake/playas deviate sufficiently from the elliptical to circular morphology to warrant exclusion from the Carolina Bay classification even though their morphologies may be in a continuum and their genesis identical.” P.F. Huddlestun}

Of course, he said "may". Regardless, it is taken as gospel these lakes present identically to the Carolina bays, adding to the gradualistic narrative. I question that narrative, and I invite you to question it also.

And similarly, the clamshell playas along the Straits Of Magellan in Chile are at best ovate on one side while the opposing side is highly irregular. LOOK... There is an oval one there!

Probably the most disingenuous comparison I have seen is from Kaczorowski's thesis. His figure 35 compares statistically rare ovoid lakes in Chile with Lake Waccamaw, a gradualistic lake that does not present even remotely like the tens of thousands of actual Carolina bays I have documented in the survey. While I find it quaint that Waccamaw is commonly called a Carolina bay, I find it quite depressing that professional geologists consider that lake as a proxy for all Carolina bays!

Unlike those lakes, the Survey DEMs show the Carolina bays to be robustly constrained to welldefined oriented ovoid planforms. No rag-tag here, no $67 \%$ fit - they are robustly cookie-cutter at all elevations and spatial expanse.

Which brings me to my most heart-felt observation of this talk. I sense that other workers consider the existence of thousands of identically shaped, kilometer-scale, oriented, and hydraulically closed basins to be unexceptional. Is such a finding so commonplace it does not even deserve to be acknowledged??? Shall we just continue with the obfuscation of their planforms? As for me, I am pursuing every venue I can to popularize the catastrophic nature of these enigmatic ovoid shapes. 
As an example of that ongoing oversight, lets revisit Herndon Bay. Perhaps rather than chasing "mud" and declaring it Cretaceous Black Creek, we should be noting that Herndon, the large basin on the lower right, is one of three cookie-cutter bays which are perfect matches to the same $1.17 \mathrm{~km}$ bayCarolina overlay. Exact, just copy and place in Google Earth. Go figure!

And each sibling bay has a correlated shadow bay which are perfect matches to the same $1.17 \mathrm{~km}$ bayCarolina overlay. Exact, just copy and place in Google Earth.

Moore did not even sample that secondary rim, yet declared the bay had actually migrated from that position while maintaining its robust planform.

Please recognize that I am proposing a Cosmic hand in this geomorphology, not a Heavenly one.

The explanation provided by Kaczorowski mandates the presence of an antecedent water-filled geometrically circular depression. He then demonstrates surficial modification using an unrealistic prevailing wind regimen which both alternates and oscillates. It has never been replicated, only excused, even by him in his unpublished thesis! What is apparent here is the creation of two opposing "Clam shell" lakes fighting to move down wind, but remaining in place because of a rigorously maintained 50-50 duty cycle of wind.

The resulting planform doesn't look remotely like any actual Carolina bay, or any actual lake on the Earth, for that matter.

Workers have used Kaczorowski's model to validate that "katabatic winds" flowing southward from the Laurentide ice sheet, and/or massive cyclonic wind fields during the glacial ages as the motive force for a "Wind \& Wave" genesis for the bays, yet none of those mechanisms deliver his duty-cycle of $180^{\circ}$ alternating wind. The only wind being delivered there is that driven by their hands waving in the air.

I call "off sides". A catastrophic solution is not complicated - it's the simplest. Bang!

\section{And finally, ... "they don't look that old!"}

We maintain that the "ideal bay" commonly investigated represents a small subset of the bays. When investigated in the LiDAR, extensive erosion is evident. We ask: what is the attraction to dating ONLY the wispy aeolian paleo dunes that cap the south-east rims? Our answer, a rather dismissive one, is that the results will likely show relatively recent surficial wind activity. It is easy to discriminate those light surficial deposits from the heavy, coarse constituents in the actual rims.

The hypothesis is satisfactorily falsified if the cosmogenic nuclide burial dating of sediments beneath the foundational rims of the Carolina bays do not yield dates consistent with a deposition $~ 800,000$ years ago. Just don't bring me dates from $150 \mathrm{~cm}$ down into the rim - try 10 meters.

$26 \mathrm{AL} / 10 \mathrm{Be}$ technology is accurate back 5 Million years, and has brought clarity to the timing of:

- Laurentian Ice Sheet maximum extents dated to over 2 Million years, as well as identifying a regolith injection $800 \mathrm{ka}$

- The enigmatic regolith pulse recorded in Appalachian Plateau karst infill was dated at 800ka

- Hickory Run Boulder Field and Paleo channel ages in Chesapeake Bay - both far older than contemplated! 


\section{The Tektites}

There exists an historical scientific imperative to embrace competing hypothesis in the face of unsolved mysteries. Beyond the Carolina bays themselves, the alternative nature of our hypothesis extends to another decades-old problem: the unsolved mystery of the Mid Pleistocene Impact astrobleme responsible for generating the vast strewn field of tektites found from the Antarctic to Madagascar, across Indochina up into China proper, as well as the Philippines, Indonesia and Australia. That emplacement of as much as 60 Billion metric tons of this distal ejecta is implicated in the termination of Homo erectus' tenure on the Sangiran dome in Java.

Isotopic evidence demands these materials were hewn from continental crust, which in our analysis is a chemical and temporal match to the upper sedimentary strata across the Lower Peninsula of Michigan.

Our analysis of trajectories for tektites ejected at velocities close to Earth escape can easily land at antipodal locations due to hang time of 5 to 10 hours. Modeled from our posited impact site, the entire Australasian strewn field is easily reachable. 


\section{Summary}

A catastrophic narrative for the genesis of the enigmatic Carolina bays is proposed. Our working hypothesis holds the Mid Pleistocene Transition Impact event of $\sim 786,000$ years ago as the source of a vast blanket of medial ejecta, where Carolina bays are mere disruptions in the surface expression of that blanket. The authors sense that the scientific community is either unaware of, or dismisses, the level of robustness to which Carolina bay planforms hold to their archetype shapes. This robustness continues to apply to heavily eroded bays which have been pirated by headward stream erosion, or buried deeply in flood plain or estuarian environments. Comparisons have been made by other workers to lacustrine environments which occasionally show as mildly oval, but those are members of a rag-tag collection of landforms which show the randomness of uniformitarian processes in their shorelines.

The hypothesis is falsified if Cosmogenic 26Al-10Be burial dating does not support an age of $\sim 800 \mathrm{ka}$ for the antecedent surface beneath the bays' formational rims.

\section{Our research is self-funded}

Authors:

Michael E. Davias, michael@cintos.org

Thomas H.S. Harris, thsharris@ mindspring.com 